\title{
FAST NEUTRON RADIOGRAPHY RESEARCH AT ANL-W
}

\author{
R. T. Klann \\ Engineering Division \\ Argonne National Laboratory \\ P.O. Box 2528 \\ Idaho Falls, ID, USA 83403-2528 \\ and \\ M. D. Natale \\ University of Massachusetts - Lowell \\ 11 Gershom Avenue \\ Lowell, MA, USA 01854 \\ Manuscript submitted to the \\ Fifth World Conference on Neutron Radiography \\ Berlin, Germany \\ June 17-20, 1996

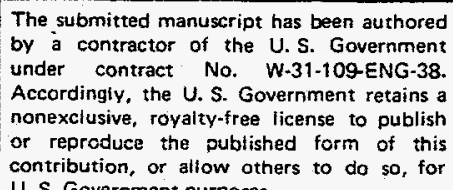

\section{DISCLAIMER}

This report was prepared as an account of work sponsored by an agency of the United States Government. Neither the United States Government nor any agency thereof, nor any of their employees, makes any warranty, express or implied, or assumes any legal liability or responsibility for the accuracy, completeness, or usefulness of any information, apparatus, product, or process disclosed, or represents that its use would not infringe privately owned rights. Reference herein to any specific commercial product, process, or service by trade name, trademark, manufacturer, or otherwise does not necessarily constitute or imply its endorsement, recommendation, or favoring by the United States Government or any agency thereof. The views and opinions of authors expressed herein do not necessarily state or reflect those of the United States Government or any agency thereof.

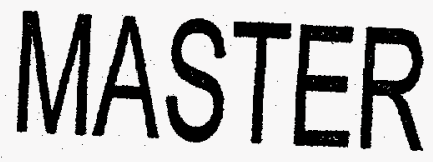

\footnotetext{
"Work supported by the United States Department of Energy, Reactor Systems, Development and Technology, under Contract W-31-109-Eng-38.
} 


\section{DISCLAMMER}

Portions of this document may be illegible in electronic image products. Images are produced from the best available original document. 
FAST NEUTRON RADIOGRAPHY RESEARCH AT ANL-W

\author{
R. T. Klann \\ Engineering Division \\ Argonne National Laboratory \\ P.O. Box 2528 \\ Idaho Falls, ID, USA 83403-2528 \\ M. D. Natale \\ University of Massachusetts - Lowell \\ 11 Gershom Avenue \\ Lowell, MA, USA 01854
}




\begin{abstract}
Thirty-seven different elements were tested for their suitability as converter screens for direct and indirect fast neutron radiography. The use of commercial $X$-ray scintillator screens containing $\mathrm{YTaO}_{4}, \mathrm{LaOBr}: \mathrm{Tm}, \mathrm{YTaO}_{4}: \mathrm{Nb}, \mathrm{YTaO}_{4}: \mathrm{Tm}, \mathrm{CaWO}_{4}$, $\mathrm{BaSO}_{4}: \mathrm{Sr}$, and $\mathrm{GdO}_{2} \mathrm{~S}: \mathrm{Tb}$ was also explored for direct fast neutron radiography.
\end{abstract}

For the indirect radiographic process, only one element, holmium, was found to be better than copper. Iron was also found to work as well as copper. All other elements that were tested were inferior to copper for indirect fast neutron radiography. For direct fast neutron radiography, the results were markedly different. Copper was found to be a poor material to use, as thirty-two of the elements performed better than the copper. Tantalum was found to be the best material to use. Several other materials that also performed remarkably well include, in order of decreasing utility, gold, lutetium, germanium, dysprosium, and thulium.

Several interesting results were obtained for the commercial X-ray scintillator screens. Most notably, useful radiographs were produced with all of the various scintillation screens. However, the screens containing $\mathrm{YTaO}_{4}: \mathrm{Nb}$ offered the greatest film densities for the shortest exposure times. Screens using $\mathrm{GdSO}_{4}: \mathrm{Tb}$ provided the best resolution and clearest images at the sacrifice of exposure time. Also, as previous researchers found, scintillator screens offered significantly shorter exposure times than activation foils.

\title{
Introduction
}

Researchers in the past (refs. 1-9) have explored fast neutron (14 MeV) radiography using activation foils, scintillating screens, and track-etch methods. Berger (refs. 7 and 8) found that copper was the best material to use for indirect radiography as it offered the highest background densities for the lowest fluence levels. However, Berger was only able to test copper, aluminum, sulfur, phosphorous, iron, silver, holmium, tantalum, and silicon due to the lack of availability of affordable, relatively pure materials. 
Additionally only two types of scintillators were tested, $\mathrm{CaWO}_{4}$ and $\mathrm{ZnS}(\mathrm{Ag})$, as these were the only commercial scintillators available at the time. Reasonable radiographs were produced with both scintillator types. Berger also demonstrated that scintillator screens were significantly better and more efficient at producing radiographs than activation foils. Richardson (ref. 9) developed a system using $\mathrm{CaWO}_{4}$ scintillator screens to radiograph warheads and rocket motors which produced radiographs with very good resolution (able to observe $1 \mathrm{~mm}$ holes).

Today, numerous activation foils are readily available as well as several new scintillator materials. These materials and foils were obtained and have been tested to determine if there are materials that offer better resolution and reduced exposure times from those previously examined.

\section{Experimental Procedure}

A versatile system for fast neutron radiography testing was designed and installed at Argonne National Laboratory (ref. 10). The system which includes a neutron generator, two support tables, a film cart, film cassettes, and lead shielding is inherently simple but offers the widest range of flexibility in specifying operating parameters. Objects as small as a coin or as large as a $1 \mathrm{~m}$ by $1 \mathrm{~m}$ box can be radiographed. The source-to-film distance can be varied from $1 \mathrm{~cm}$ up to $1.5 \mathrm{~m}$ by repositioning the film cart on the sample table. For distances greater than $1.5 \mathrm{~m}$, the sample table can be separated from the source table so that the source-to-film distance is only limited by the size of the room in which it is located. The neutron source is an MF Physics A-711 neutron generator which produces $2.98 \times 10^{10}$ neutrons per second (at a setting of $150 \mathrm{kV}$ and $2.5 \mathrm{~mA}$ ) with an average energy of $14.55 \mathrm{MeV}$ (ref. 11).

To perform the indirect radiography tests, small activation foils (approximately 2.5 $\mathrm{cm} \times 2.5 \mathrm{~cm})$ were mounted on sheets of cardboard $(18 \mathrm{~cm} \times 43 \mathrm{~cm}) .37$ different foils were used including: $\mathrm{Ag}, \mathrm{Al}, \mathrm{Au}, \mathrm{Cd}, \mathrm{Ce}, \mathrm{Cu}, \mathrm{Dy}, \mathrm{Er}, \mathrm{Eu}, \mathrm{Fe}, \mathrm{Gd}, \mathrm{Ge}, \mathrm{Hf}, \mathrm{Ho}$, In, Ir, Lu, Mo, Nb, Nd, Ni, Pb, Pd, Pr, Pt, Re, Sm, Sn, Ta, Tb, Ti, Tm, V, W, Yt, Zn, and $\mathrm{Zr}$. The foil thicknesses were typically $0.25 \mathrm{~mm}$ thick but the actual thicknesses are as shown in Table 1 . Four or five foils along with a copper reference foil were mounted in the center of each card. The cards were then individually placed into an aluminum cassette for irradiation. The cassette was placed into the film cart and positioned $10 \mathrm{~cm}$ from the neutron generator. Each card was irradiated for 60 minutes and placed on Kodak Industrex ${ }^{\circledR}$ SR radiography film within 5 minutes from the end of exposure. The foils were in direct contact with the film. The cards remained on the film overnight and were developed the next day. This method was chosen because it is the same process that is used at Argonne National Laboratory for thermal neutron radiography using dysprosium and indium foils and represents a routine industrial process.

For the direct radiography tests using activation foils, the same series of cards were used. Each card was placed into a light-tight DuPont Cronex ${ }^{\circledR}$ cassette along with a piece of Kodak Industrex ${ }^{\circledR} \mathrm{SR}$ radiography film. The aluminum cassettes were not used because they are not light-tight as they were designed for indirect radiography only. Once again, the foils were placed directly in contact with the 
film. The cassette was then loaded into the film cart and positioned $10 \mathrm{~cm}$ from the neutron generator. The foils and film were irradiated for 30 minutes. The film was then removed from the cassette and promptly processed according to the manufacturers instructions.

To study the scintillating screens, the film cassettes were modified to include a thin $1.5 \mathrm{~mm}$ piece of plastic to produce protons from the neutron beam through elastic scattering from hydrogen and other low $Z$ materials in the plastic. Each cassette was loaded as follows from front to back: plastic sheet, front screen, film, label, and back screen. The cassette was then loaded into the film cart with the front facing the neutron generator. The cart was positioned so that the source-to-film distance was $50 \mathrm{~cm}$. The cassettes were exposed for 3 minutes with the neutron generator at a setting of $150 \mathrm{kV}$ and $2.5 \mathrm{~mA}$. The film was then removed from the cassette and promptly processed according to the manufacturers instructions.

\section{Results}

Because it was physically impossible to irradiate all the materials for each test in one exposure, exposure conditions were slightly different between irradiations due to slight variances in process parameters. Due to these variances between irradiations, a method of comparison between the runs was developed.

Film density is a logarithmic function of the intensity of incident exposure on the film to the intensity of transmitted exposure from the film, such that $D=\log _{10}\left(1 / I_{0}\right)$ (ref. 12). It is a relation that can be used to predict exposure times or fluence levels necessary to obtain a given density once $I_{0}$ is known from a previous exposure. $I_{0}$ is a function of a given operation when conditions (such as foil type, film type, and processing parameters) are maintained constant. Therefore, by maintaining the conditions constant (as in the irradiation and processing of one card), $I_{0}$ for each material on that card can be compared. This is appropriate because $I_{0}=1 \cdot 10^{-D}$, where $I$ is a constant for a given card and $D$ is the density measured for each material. $I_{0}$ can then be used to relate each material on a card to one another, i.e. the lower the $I_{0}$ the lower the exposure required for a given density and the better the material. However, because $I$ is not constant from exposure to exposure, $I_{0}$ cannot be directly used to relate the results from different cards. For this purpose, the ratio of $I_{0}$ for a material to $I_{0}$ for the reference copper sample from the same card is used. The ratio, which is equal to $10^{(D c-D m)}$ where $D_{c}$ is the density of the copper and $D_{m}$ is the density of the material of interest, can then be compared for each material. If the ratio is less than one, than the material is better than copper, i.e. the material requires less exposure than copper to obtain the same density. If the ratio is greater than one, the material is worse than copper. Now, assuming a reference value for $I_{0}$ for copper (i.e. referencing all values to a standard exposure and identical processing conditions), then all of the materials can be directly compared.

Results for the indirect radiography tests of 37 different elements are listed in Table 1. Note that only holmium was shown to be better than copper while steel was shown to work as well as copper. For these tests the average $I_{0}$ for copper was found to be $1.65 \times 10^{9} \mathrm{n} / \mathrm{cm}^{2}$ so that an exposure of $5.22 \times 10^{10} \mathrm{n} / \mathrm{cm}^{2}$ is required for 
a density of 1.5. This number is comparable to Berger's best result (ref. 7) of $1.26 \times 10^{10} \mathrm{n} / \mathrm{cm}^{2}$. The difference is due to differences in film type, foil thicknesses, and processing conditions. What is most notable is the relative rankings of the materials. Of the similar materials tested, Berger (ref. 8) ranked the materials as follows: $\mathrm{Cu}, \mathrm{Al}, \mathrm{Fe}, \mathrm{Ag}, \mathrm{Ho}, \mathrm{Ta}$; whereas, Table 1 indicates a ranking of: $\mathrm{Ho}, \mathrm{Cu}$, $\mathrm{Fe}, \mathrm{Al}, \mathrm{Ag}, \mathrm{Ta}$.

Table 1

Ratio of Intensities for Indirect Radiography

\begin{tabular}{|c|c|c|c|c|c|}
\hline Element & $\begin{array}{c}\text { Thickness } \\
(\mathrm{mm})\end{array}$ & $I_{0} / I_{C}$ & Element & $\begin{array}{l}\text { Thickness } \\
(\mathrm{mm})\end{array}$ & $I_{0} / I_{c}$ \\
\hline Ho & 0.254 & 0.955 & $\mathrm{Cd}$ & 0.254 & 1.096 \\
\hline $\mathrm{Cu}$ & 0.254 & 1.000 & $\mathrm{Gd}$ & 0.254 & 1.096 \\
\hline $\mathrm{Fe}$ & 0.254 & 1.000 & $\mathrm{Hf}$ & 0.254 & 1.096 \\
\hline $\mathrm{Al}$ & 0.254 & 1.023 & Mo & 0.254 & 1.096 \\
\hline In & 0.762 & 1.023 & $Y t$ & 0.249 & 1.096 \\
\hline $\mathrm{Ag}$ & 0.249 & 1.047 & $\mathrm{Zr}$ & 0.254 & 1.096 \\
\hline Ir & 0.254 & 1.047 & $\mathrm{Er}$ & 0.254 & 1.122 \\
\hline $\mathrm{Re}$ & 0.249 & 1.047 & $\mathrm{Ni}$ & 0.249 & 1.122 \\
\hline $\mathrm{Pd}$ & 0.249 & 1.047 & $\mathrm{~Pb}$ & 0.254 & 1.122 \\
\hline $\mathrm{Zn}$ & 0.249 & 1.047 & $\operatorname{Pr}$ & 0.249 & 1.122 \\
\hline $\mathrm{Au}$ & 0.254 & 1.072 & Sn & 0.249 & 1.122 \\
\hline Dy & 0.076 & 1.072 & $\mathrm{Ti}$ & 0.249 & 1.122 \\
\hline Eu & 0.254 & 1.072 & V & 0.254 & 1.122 \\
\hline $\mathrm{Ge}^{(1)}$ & 0.102 & 1.072 & W & 0.249 & 1.122 \\
\hline Lu & 0.127 & 1.072 & $\mathrm{Ce}$ & 0.254 & 1.148 \\
\hline Nd & 0.254 & 1.072 & $\mathrm{Nb}$ & 0.249 & 1.148 \\
\hline Pt & 0.254 & 1.072 & $\mathrm{~Tb}$ & 0.249 & 1.148 \\
\hline $\mathrm{Sm}$ & 0.249 & 1.072 & $\mathrm{Tm}$ & 0.249 & 1.148 \\
\hline $\mathrm{Ta}$ & 0.254 & 1.072 & & & \\
\hline
\end{tabular}

(1/The Ge results noted here are for an alloy of $\mathrm{Au}-\mathrm{Ge}(88: 12 \mathrm{wt} \%)$.

Results for the direct radiography tests are shown in Table 2. Most remarkable is the fact that copper is a very poor material to use as most of the materials reported have ratios much less than one. However, it was found that the cardboard backing was adding appreciably to the exposure due to protons from elastic scattering from hydrogen and other low $Z$ materials in the cardboard. Therefore, the densities measured for each material are representative of exposure due to activation of the 
material and proton shielding from the material. Because of this secondary effect, the ten best materials, along with copper, were re-shot using a thin aluminum backing instead of the cardboard. Aluminum was used because it was available and had one of the lower ratios as noted in Table 2. The results shown in Table 3 using the aluminum backing were markedly different than those shown in Table 2 using the cardboard backing. Most notably, the ranking of dysprosium dropped. This is due to the thickness of the dysprosium foil compared to the other foils. The dysprosium foil was much thinner than the other foils and as such was not as good of a proton shield as the other foils. Therefore, the proton exposure (an interference reaction) was a larger percentage of the total exposure of the film. By removing the proton source, the exposures and ultimate rankings of the materials are more representative of exposures only from the foils. The exposures are not completely due to the foils because of activation of the aluminum backing. However, this is a much smaller effect, as the background density of the film is less than the density from the copper foil.

Table 2

Ratio of Intensities for Direct Radiography (samples mounted on cardboard)

\begin{tabular}{|c|c|c|c|}
\hline Element & $I_{0} / I_{c}$ & Element & $I_{0} / I_{C}$ \\
\hline Dy & 0.123 & Al & 0.550 \\
\hline $\mathrm{Ta}$ & 0.195 & $\mathrm{Pt}$ & 0.575 \\
\hline $\mathrm{Au}$ & 0.214 & $\mathrm{Gd}$ & 0.575 \\
\hline $\mathrm{Ge}$ & 0.245 & $\mathrm{Ni}$ & 0.575 \\
\hline $\mathrm{Lu}$ & 0.251 & W & 0.603 \\
\hline $\mathrm{Tm}$ & 0.275 & $\mathrm{Pr}$ & 0.617 \\
\hline $\mathrm{Nd}$ & 0.302 & Ir & 0.646 \\
\hline $\mathrm{Cd}$ & 0.324 & Mo & 0.692 \\
\hline $\mathrm{Tb}$ & 0.331 & V & 0.692 \\
\hline Sn & 0.339 & $\mathrm{Re}$ & 0.724 \\
\hline $\ln$ & 0.389 & $Y t$ & 0.741 \\
\hline $\mathrm{Pb}$ & 0.417 & $\mathrm{Ti}$ & 0.759 \\
\hline $\mathrm{Sm}$ & 0.417 & $\mathrm{Zn}$ & 0.759 \\
\hline Ho & 0.427 & $\mathrm{Zr}$ & 0.794 \\
\hline $\mathrm{Ce}$ & 0.427 & $\mathrm{Cu}$ & 1.000 \\
\hline $\mathrm{Nb}$ & 0.490 & $\mathrm{Fe}$ & 1.023 \\
\hline Er & 0.537 & $\mathrm{Pd}$ & 1.047 \\
\hline$H f$ & 0.537 & $\mathrm{Ag}$ & 5.623 \\
\hline
\end{tabular}


Table 3

Ratio of Intensities for Direct Radiography

(samples mounted on aluminum sheet)

\begin{tabular}{|c|c|c|}
\hline Element & $\mathrm{I}_{0} / \mathrm{I}_{\mathrm{c}}$ & Exposure to obtain $\mathrm{D}=1.5$ \\
\hline $\mathrm{Ta}$ & 0.141 & $4.75 \times 10^{9} \mathrm{n} / \mathrm{cm}^{2}$ \\
\hline $\mathrm{Au}$ & 0.174 & $5.86 \times 10^{9}$ \\
\hline $\mathrm{Lu}$ & 0.251 & $8.45 \times 10^{9}$ \\
\hline $\mathrm{Ge}$ & 0.263 & $8.86 \times 10^{9}$ \\
\hline $\mathrm{Dy}$ & 0.331 & $1.11 \times 10^{10}$ \\
\hline $\mathrm{Tm}$ & 0.331 & $1.11 \times 10^{10}$ \\
\hline $\mathrm{Tb}$ & 0.447 & $1.51 \times 10^{10}$ \\
\hline $\mathrm{Nd}$ & 0.513 & $1.73 \times 10^{10}$ \\
\hline $\mathrm{Cd}$ & 0.603 & $2.03 \times 10^{10}$ \\
\hline $\mathrm{Sn}$ & 0.724 & $2.44 \times 10^{10}$ \\
\hline $\mathrm{Cu}$ & 1.000 & $3.37 \times 10^{10}$ \\
\hline
\end{tabular}

Table 4

Results of Scintillator Screen Tests

\begin{tabular}{|c|c|c|c|}
\hline Screen $^{(1)}$ & Scintillator & $\begin{array}{l}\text { Background } \\
\text { Density }\end{array}$ & $\begin{array}{l}\text { Exposure } \\
\text { for } D=1.5\end{array}$ \\
\hline DuPont Quanta ${ }^{\circledast}$ Super Rapid & $\mathrm{YTaO}_{4}: \mathrm{Nb}$ & 3.06 & $4.52 \times 10^{6} \mathrm{n} / \mathrm{cm}^{2}$ \\
\hline DuPont Quanta ${ }^{\oplus}$ Rapid & $\mathrm{YTaO}_{4}: \mathrm{Nb}$ & 2.99 & $5.31 \times 10^{6}$ \\
\hline DuPont Cronex Quanta III & LaOBr:Tm & 2.95 & $5.82 \times 10^{6}$ \\
\hline $\begin{array}{l}\text { DuPont Ultra-Vision }{ }^{\circledR} \text { Detail } \\
\text { (front) and Quanta }{ }^{\circledR} \text { Super Rapid } \\
\text { (back) }\end{array}$ & $\mathrm{YTaO}_{4}$ & 2.92 & $6.24 \times 10^{6}$ \\
\hline DuPont Ultra-Vision ${ }^{\oplus}$ Rapid & $\mathrm{YTaO}_{4}$ & 2.90 & $6.53 \times 10^{6}$ \\
\hline DuPont Cronex ${ }^{\circledR}$ SR-342 & $\mathrm{CaWO}_{4}$ & 2.68 & $1.08 \times 10^{7}$ \\
\hline DuPont Quanta ${ }^{\circledR}$ Fast Detail & $\mathrm{YTaO}_{4}: \mathrm{Tm}$ & 2.62 & $1.24 \times 10^{7}$ \\
\hline Kodak X-Omatic ${ }^{@}$ Regular & $\mathrm{BaSO}_{4}: \mathrm{Sr}$ & 2.27 & $2.79 \times 10^{7}$ \\
\hline DuPont Par-Speed ${ }^{\circledR}$ & unknown & 1.86 & $7.16 \times 10^{7}$ \\
\hline Kodak Lanex ${ }^{\circledR}$ Fine & $\mathrm{GdO}_{2} \mathrm{~S}: \mathrm{Tb}$ & 1.61 & $8.30 \times 10^{7}$ \\
\hline
\end{tabular}

"DuPont Cronex ${ }^{\circledR} 10 \mathrm{TL}$ medical $x$-ray film was used with all screens with the following exceptions:

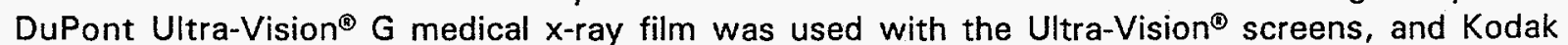
T-Mat ${ }^{\oplus}$ G/RA diagnostic film was used with the Lanex ${ }^{\oplus}$ Fine screens.

${ }^{(2)}$ All screens, with the exception of the Kodak Lanex ${ }^{\circledR}$ Fine screens, were exposed at a distance of $50 \mathrm{~cm}$ for 3 minutes for a total exposure of $1.64 \times 10^{8} \mathrm{n} / \mathrm{cm}^{2}$. The exposure for the Kodak Lanex ${ }^{\circledast}$ Fine screens was at a distance of $140 \mathrm{~cm}$ for 15 minutes for a total exposure of $1.07 \times 10^{8} \mathrm{n} / \mathrm{cm}^{2}$. 
Also shown in Table 3 are the exposures required to obtain a background density of 1.5 using each material. Note that all of the materials tested still require less exposure than copper. The best, tantalum, is approximately a factor of seven better than copper. This means that for a given density, the tantalum exposure would only require one-seventh the time or more importantly the source-to-film distance could be increased by a factor of 2.6 resulting in better resolution for the same exposure time.

Results for the direct radiography tests are shown in Table 4. It should be noted that all of the screens produced acceptable radiographs. As shown in the table, the DuPont Quanta ${ }^{\circledR}$ Super Rapid and Rapid screens which use niobium-doped yttrium tantallate as the scintillating material required the least exposure to obtain a density of 1.5, while some of the older scintillator types, such as calcium tungstate, required considerably more exposure. The Kodak Lanex ${ }^{\circledR}$ Fine screens, which use gadolinium oxysulfide as the scintillating material, required the largest exposure to

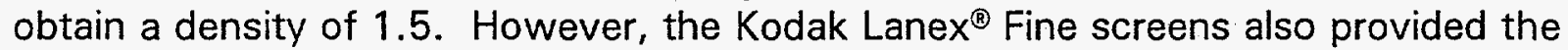
best resolution. $0.8 \mathrm{~mm}$ holes were observable in $1.25 \mathrm{~cm}$ thick blocks of polyethylene and steel (ref. 13).

\section{Conclusions}

A comparison between the different radiographic methods for fast neutrons is shown in Table 5 . The fastest converter screens are clearly $x$-ray scintillator screens. Results shown in Table 5 also include exposure results calculated by previous researchers. As noted in the table, the new DuPont screens require less exposure than Richardson's results (ref. 9), however, the resolution is not as good (ref. 13). The new system using Kodak Lanex ${ }^{\circledR}$ Fine screens requires more exposure than Richardson's system (ref. 9), however, the resolution is better - 0.8 $\mathrm{mm}$ holes are observable compared to $1 \mathrm{~mm}$ holes (ref. 13).

Any of the elements listed in Table 1 can produce radiographs with enough exposure time, however, $x$-ray scintillating screens are significantly faster (by as much as 1000 times for direct radiography and by as much 10000 times for indirect radiography). Therefore, it makes little sense to use activation foils. There are only two possible benefits of using activation foils - resolution improvement and radiography of radioactive samples. Film resolution using activation foils was not addressed in this study, however, it is not suspected that significant improvements in resolution would be gained over the $x$-ray scintillating screens. Therefore, the only real benefit of using foils would be for the radiography of radioactive samples. This is significant, as numerous researchers have demonstrated that the indirect foil-transfer method is a necessity for thermal neutron radiography of irradiated reactor fuels. A real benefit for fast neutron radiography using the indirect foil-transfer method has yet to be demonstrated. 
Table 5

Comparison Between Radiographic Methods

\begin{tabular}{||c|c|c||}
\hline $\begin{array}{c}\text { Radiographic } \\
\text { Method }\end{array}$ & Converter Screen & $\begin{array}{c}\text { Exposure Required } \\
\text { to obtain } \mathrm{D}=1.5 \\
\left(\mathrm{n} / \mathrm{cm}^{2}\right)\end{array}$ \\
\hline \hline Indirect & Holmium foil & $5.0 \times 10^{10}$ \\
\hline Indirect & Double Cu foils ${ }^{(1)}$ & $1.3 \times 10^{10}$ \\
\hline Direct & Tantalum foil $^{2}$ & $4.8 \times 10^{9}$ \\
\hline Direct & Kodak Lanex $^{\oplus}$ Fine & $8.3 \times 10^{7}$ \\
\hline Direct & DuPont Cronex ${ }^{\circledR}$ Lightning Plus & $6.0 \times 10^{6}$ \\
\hline Direct & DuPont Quanta ${ }^{\circledR}$ Super Rapid & $4.5 \times 10^{6}$ \\
\hline
\end{tabular}

${ }^{11}$ Berger (ref. 8) using Kodak-Pathe Kodire ${ }^{\circledR} \mathrm{x}$-ray film

${ }^{(2)}$ Richardson (ref. 9) using Kodak RP/R54 Royal ${ }^{\circledR}$ X-Omat medical $x$-ray film 


\section{References}

1. E.L. Criscuolo and D. Polansky, "Fast Neutron Radiography," Proceedings of the Missiles and Rockets Symposium, p. 112-115, U.S. Naval Ammunition Depot, Concord, California, April, 1961.

2. D. Polansky and E.L. Criscuolo, "Radiographic Aspects of Fast Neutron Detection," Proceedings of the 24th National Conference of the American Society for Nondestructive Testing, Evanston, Illinois, 1964.

3. J. Anderson, S.B. Osborn and R.W.S. Tomlinson, "Neutron Radiography in Man," British Journal of Radiology, Vol. 37, p. 957-958, 1964.

4. E. Tochilin, "Photographic Detection of Fast Neutrons: Application to Neutron Radiography," Physics in Medicine and Biology, Vol. 10, p. 477-490, 1965.

5. D.E. Wood, "Fast Neutron Radiography with a Neutron Generator," Transactions of the American Nuclear Society, vol. 10, p. 423-444, American Nuclear Society, Incorporated, 1967.

6. P.B. Parks, et al., "Problems of Fast Neutron Radiography," Biomedical Sciences Instrumentation 6, p. 118-126, 1969.

7. H. Berger, "Some Experiments in Fast Neutron Radiography," Materials Evaluation 27, p. 245-253, December, 1969.

8. H. Berger, "Image Detection Methods for $14.5 \mathrm{MeV}$ Neutrons: Techniques and Applications," International Journal of Applied Radiation and Isotopes 21, p. 59-70, February, 1970.

9. A.E. Richardson, "Improved Images in $14.5 \mathrm{MeV}$ Neutron Radiography," Materials Evaluation 35, p. 52-58, April, 1977.

10. R.T. Klann, "A System for Fast Neutron Radiography," Proceedings of the Fifth International Conference on Applications of Nuclear Techniques, Crete, Greece, June, 1996.

11. R.T. Klann and M.D. Natale, "Determining the Flux and Average Neutron Energy from a Neutron Generator," Transactions of the American Nuclear Society, I.O. Macke, ed., vol. 74, American Nuclear Society, Incorporated, 1996.

12. P. von der Hardt and H. Rottger, ed., Neutron Radiography Handbook, p. 25-27, D. Reidel Publishing Company, Dordrecht, Holland, 1981.

13. R.T. Klann, "Fast Neutron (14.5 MeV) Radiography: A Comparative Study," Neutron Radiography (5) - Proceedings of the Fifth World Conference, paper included in these proceedings. 